\section{Response to: 'Correspondence on 'Risk of venous thromboembolism in knee, hip and hand osteoarthritis: a general population-based cohort study" by Lin et al}

Lin $e a^{1}{ }^{1}$ raised three points with regard to residual confounding to affect our findings. Below we provide point-by-point replies to the three comments.

First, we agree that immobilisation duration is a strong risk factor for postoperative venous thromboembolism (VTE). The aim of our study was to examine the relation of incident osteoarthritis $(\mathrm{OA})$ to the risk of VTE (ie, the total effect) and to assess to what extent the effect of incident OA on the risk of VTE is through its effect on knee/ hip replacement (ie, the indirect effect). ${ }^{2}$ Since postoperative immobilisation after knee/hip replacement is an intermediate variable, but not a confounder, between incident knee/hip OA and VTE, we felt it is inappropriate to adjust postoperative duration when the study goal is to assess the total effect of incident knee/hip/hand OA on the risk of VTE. ${ }^{3}$

Second, we also agree that postoperative thromboprophylaxis is crucial for reducing VTE after joint replacement. We commented in the discussion section that 'more efforts (eg, early mobilisation following surgery) are still needed to further reduce the risk of VTE after surgery'. However, like postoperative immobility, thromboprophylaxis therapy after joint replacement is an intermediate variable between incident OA and VTE; thus, it should not be adjusted for when the goal is to assess the total effect of incident OA on the risk of VTE.

Third, Lin $e t ~ a l^{1}$ suggested that we should use Caprini risk score to match incident OA patients to their comparators so two cohorts were more comparable. First, Caprini risk score is a tool to assess the risk of VTE for inpatients but not for outpatients. Matching by surgery after incident knee/hip/hand OA diagnosis is akin to adjusting for intermediate variable. In addition, we adjusted several potential risk factors (ie, risk factors that occurred before diagnosis of incident knee/hip/hand OA) that were included in calculation of Caprini risk score, such as age, body mass index, comorbidities and surgery, in the multivariable Cox proportional hazard model. Nevertheless, the residual confounding (eg, severity of comorbidities) can never be ruled out in any observational study as we have acknowledged in the limitation section.

\footnotetext{
Chao Zeng, ${ }^{1,2,3,4}$ Zidan Yang, ${ }^{4}$ Guanghua Lei $\odot, ~ 1,4,5$ Yuqing Zhang ${ }^{2,3}$ 'Department of Orthopaedics, Xiangya Hospital, Central South University, Changsha, China

2Division of Rheumatology, Allergy, and Immunology, Department of Medicine, Massachusetts General Hospital, Harvard Medical School, Boston, Massachusetts, USA

${ }^{3}$ The Mongan Institute, Massachusetts General Hospital, Harvard Medical School, Boston, Massachusetts, USA
}

${ }^{4}$ Hunan Key Laboratory of Joint Degeneration and Injury, Changsha, China ${ }^{5}$ National Clinical Research Center of Geriatric Disorders, Xiangya Hospital, Central South University, Changsha, China

Correspondence to Guanghua Lei, Department of Orthopaedics, Xiangya Hospital, Central South University, 87 Xiangya Road, Changsha, Hunan, China; lei_guanghua@csu.edu.cn and Yuqing Zhang, Division of Rheumatology, Allergy, and Immunology, Department of Medicine, Massachusetts General Hospital, Harvard Medical School, 55 Fruit Street, Boston, MA 02114, USA; yzhang108@mgh.harvard.edu

Correction notice This article has been corrected since it published Online First. The provenance and peer review statement has been included.

Handling editor Josef S Smolen

Acknowledgements Everyone who contributed significantly to the work has been listed.

Contributors All authors have read, provided critical feedback on intellectual content and approved the final manuscript.

Funding The authors have not declared a specific grant for this research from any funding agency in the public, commercial or not-for-profit sectors.

Competing interests None declared.

Patient and public involvement Patients and/or the public were not involved in the design, or conduct, or reporting, or dissemination plans of this research.

Patient consent for publication Not required.

Provenance and peer review Commissioned; internally peer reviewed.

(c) Author(s) (or their employer(s)) 2021. No commercial re-use. See rights and permissions. Published by BMJ.

\section{Check for updates}

To cite Zeng C, Yang Z, Lei G, et al. Ann Rheum Dis Epub ahead of print: [please include Day Month Year]. doi:10.1136/annrheumdis-2020-219747

Received 22 December 2020

Accepted 23 December 2020

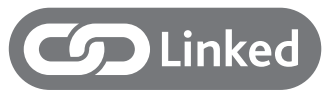

- http://dx.doi.org/10.1136/annrheumdis-2020-219733

Ann Rheum Dis 2021;0:1. doi:10.1136/annrheumdis-2020-219747

ORCID iDs

Guanghua Lei http://orcid.org/0000-0003-2987-138X

Yuqing Zhang http://orcid.org/0000-0001-7638-0888

\section{REFERENCES}

1 Lin T, Pan L, Jong G. Correspondence on "Risk of venous thromboembolism in knee, hip and hand osteoarthritis: a general population-based cohort study". Ann Rheum Dis 2020.

2 Zeng C, Bennell K, Yang Z, et al. Risk of venous thromboembolism in knee, hip and hand osteoarthritis: a general population-based cohort study. Ann Rheum Dis 2020;79:1616-24.

3 Zhang Y, Neogi T, Hunter D, et al. What effect is really being measured? An alternative explanation of paradoxical phenomena in studies of osteoarthritis progression. Arthritis Care Res 2014;66:658-61. 